\title{
Effects of heat treatments on microstructure and properties of Ti-6Al-4V ELI alloy fabricated by electron beam melting (EBM)
}

Authors: Haize Galarraga ${ }^{1}$, Robert J. Warren*1, Diana A. Lados ${ }^{1}$, Ryan R. Dehoff ${ }^{2,3}$, Michael M. Kirka ${ }^{2,3}$, Peeyush Nandwana ${ }^{2,3}$

${ }^{1}$ Worcester Polytechnic Institute, Integrative Materials Design Center, 100 Institute Road, Worcester, MA 01609, USA

${ }^{2}$ Materials Science and Technology Division, Oak Ridge National Laboratory, Oak Ridge, TN 37831, USA

${ }^{3}$ Manufacturing Demonstration Facility, Oak Ridge National Laboratory, Knoxville, TN 37932, USA

*Corresponding Author: E-mail address: rwarren@wpi.edu

\section{Abstract}

Electron beam melting (EBM) is a metal powder bed fusion additive manufacturing ( $A M$ ) technology that is used to fabricate three-dimensional near-net-shaped parts directly from computer models. Ti-6Al-4V is the most widely used and studied alloy for this technology and is the focus of this work in its ELI (Extra Low Interstitial) variation. Microstructure evolution and its influence on the mechanical properties of the alloy in the as-fabricated condition have been documented by various researchers. In the present work, different heat treatments were performed based on three approaches in order to study the effects of heat treatments on the unique microstructure formed during the EBM fabrication process. In the first approach, the effect of various cooling rates after the solutionizing process was studied. In the second approach, a correlation between the variation of $\alpha$ lath thickness during aging and the subsequent effect on mechanical properties was established. Lastly, several combined solutionizing and aging experiments were conducted; the results will be systematically discussed in the context of structural performance and design.

KEYWORDS: additive manufacturing; electron beam melting; Ti-6Al-4V; microstructure evolution; mechanical characterization; heat treatment.

\section{Introduction}

Electron beam melting (EBM) is a metal powder bed fusion additive manufacturing (AM) technology used for the fabrication of three-dimensional near-net-shaped functional components directly from computer models [1]. ASTM F2792 defines AM as "a process of joining materials to make objects from 3D model data, usually layer upon layer, as opposed to subtractive manufacturing methodologies" [2]. The use of AM technologies in general, and of EBM in particular, is experiencing a considerable increase in the variety and quantity of applications. As the technologies improve and develop, a wider range of industries are studying and implementing these technologies to manufacture an increasingly diverse range of products. Biomedical implant applications and structural aerospace parts are the most promising areas for EBM technology. However, the development of EBM technology in these areas is 
slowed down by the lack of fundamental knowledge, consistent databases, and standardization which are all critical in these industry sectors [3-7].

EBM's working principle consists of consecutive cycles where complex parts are fabricated layer by layer. Each solid material level is formed after a metallic powder layer is dispensed and selectively melted. The energy source for the melting process is an electron beam emitted from a tungsten filament. This beam is controlled by two magnetic coils, which focus and control the position and diameter of the beam. The manufacturing parameters are generated and controlled by software in order to fabricate sound parts with improved mechanical properties, low porosity and surface roughness, and optimized geometrical reproducibility. This software creates scanning algorithms based on the geometry of the part to be manufactured. The main parameters controlled by the software are: minimum and maximum beam current, number of times the beam scan is to be repeated, scanning speed of the electron beam, distance between individual scan lines (line offset), line order for the hatch pattern, and rotation angle between consecutive hatches [8].

Microstructure evolution and mechanical properties have been studied for Ti-6Al-4V alloys due to its versatility resulting from the good balance between mechanical properties, castability, plastic workability, heat treatability, and weldability [9]. Ti-6Al-4V has been broadly applied in industry and studied in the laboratory, resulting in an extensive knowledgebase relative to other metal alloys fabricated by this technology. Heat treatment of AM Ti-6Al-4V for different technologies has been extensively studied with the purpose of relieving stress and achieving an equilibrium microstructure, eliminating the metastable $\alpha^{\prime}$ martensite phase and obtaining a microstructure with exclusively $\alpha$ and $\beta$ phases [10]. However for the EBM technology, the relation between microstructure and mechanical properties has been mainly limited to the as-fabricated condition, except for some cases where hot isostatic pressing (HIP) was applied to the EBM parts. The EBM process, similarly to other AM processes, does not completely prevent the presence of porosity in the build. Therefore, in order to mitigate the disadvantages caused by these defects, the effect of HIP treatment has been studied [11-19]. The biggest interest for the study of the mechanical properties in the as-fabricated condition is that the EBM process, unlike other metal AM technologies such as selective laser melting (SLM) or laser engineered net shaping (LENS), does not require heat treatment to obtain reasonable ductility and low residual stresses. The high temperature of the fabrication chamber in the EBM process prevents the presence of brittle $\alpha^{\prime}$ martensitic phase from forming in the final microstructure, while the slow cooling rates from the chamber temperature to room temperature, relieves most of the residual stress generated during the additive manufacturing process [11].

Ti-6Al-4V is an $\alpha+\beta$ alloy because $\alpha$ and $\beta$ microstructural phases coexist at room temperature. The $\alpha+\beta$ alloys are interesting because they combine the strength of $\alpha$ alloys with the ductility of $\beta$ alloys, and their microstructures and properties can be varied widely by appropriate heat treatments and thermomechanical processing [20]. The current study focuses on understanding the effect of different heat treatments on the unique microstructure of the EBM Ti-6AI-4V ELI (Extra Low Interstitial) and its impact on mechanical properties. The heat treatments studied in this work were addressed using three approaches. The first investigated the effect of the solution heat treatment and subsequent cooling rate on the formation of different microstructural phases and their morphology. The second studied the effect of the aging time and temperature on $\alpha$ lath thickness and mechanical properties. The third approach assessed the effect of solutionizing and aging heat treatment on the microstructure and properties of the material. 


\section{Materials and methodology}

\subsection{Materials and processing conditions}

The EBM build used for this study was manufactured from Ti-6AI-4V ELI gas atomized powder provided by Arcam. The ELI variant of Ti-6Al-4V contains reduced levels of oxygen, nitrogen, carbon, and iron as shown in Table 1. The powder used was a mixture of $50 \%$ new powder and $50 \%$ powder reused from a previous build, with a particle diameter ranging from 45 to $150 \mu \mathrm{m}$, Figure 1 [21]. It is important to note that reused powder, which is kept under vacuum for the time between builds, can still exhibit an increase in oxygen levels which can affect the subsequent microstructure and mechanical properties of the final part [22]. A study by Nandwana et al. [23] showed that standard Ti-6Al-4V powder exposed to an electron beam for 150 hours experience an increase in oxygen levels from 0.141 to 0.168 wt.\% which is within the specification for the alloy. Since ELI Ti-6Al-4V powder has a much lower oxygen content to begin with, it can be safely assumed that using a mixture of $50 \%$ reused powder will not result in a compromised final product. The EBM manufacturing parameters of the build (spot size, scan velocity, sintering path, etc.) were defined by an internal algorithm of the Arcam Q10 machine. The process consists of preheating to a chamber temperature of $650^{\circ} \mathrm{C}$ which is maintained throughout the build. Each scanning layer was $50 \mu \mathrm{m}$ thick and the average scanning time per layer was one minute for this batch. The total build time was 2200 minutes ( 36 hours and 40 minutes). All of the post build heat treatments for this study were carried out using a Thermo Scientific $1.8 \mathrm{~kW}$ Lindberg/Blue furnace.

Table 1. Standard chemical composition [24] and actual chemical composition of the powder provided by Arcam [25]

\begin{tabular}{ccccccccc} 
& Al & $\mathbf{V}$ & $\mathbf{C}$ & $\mathbf{F e}$ & $\mathbf{0}$ & $\mathbf{N}$ & $\mathbf{H}$ & $\mathbf{T i}$ \\
\hline $\begin{array}{c}\text { Ti-6Al-4V ELI } \\
\text { (Standard) }\end{array}$ & $5.5-6.5 \%$ & $3.5-$ & $<0.08 \%$ & $<0.25 \%$ & $<0.13 \%$ & $<0.05 \%$ & $<0.012 \%$ & Balance \\
\hline $\begin{array}{c}\text { Ti-6Al-4V ELI } \\
\text { (Arcam) }\end{array}$ & $6.0 \%$ & $4.0 \%$ & $0.03 \%$ & $0.1 \%$ & $0.1 \%$ & $0.01 \%$ & $<0.003 \%$ & Balance \\
\hline
\end{tabular}

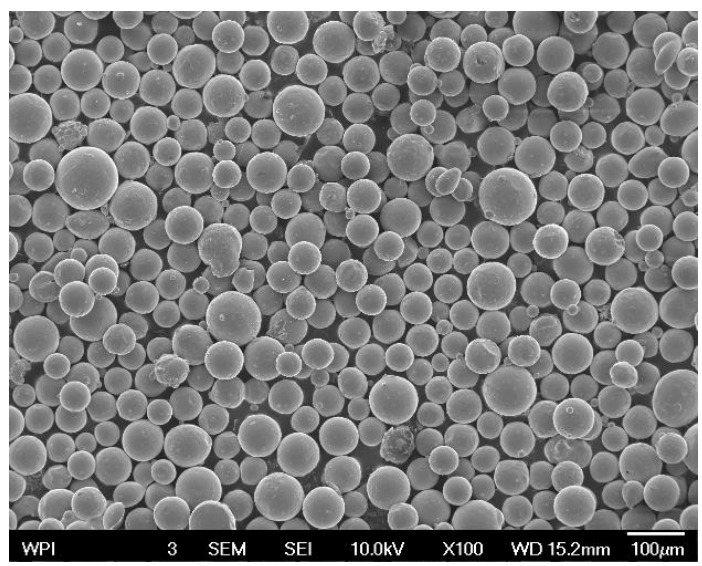

Figure 1. Ti-6Al-4V ELI powder particles used to fabricate the EBM samples in this study [21].

\subsection{Specimen locations and preparation}

The build configuration and AM reference axis system on the build platform of the Arcam machine is shown in Figure 2. The cylindrical specimens $(\varnothing 15 \mathrm{~mm} \times 105 \mathrm{~mm}$ ) are orientated with their longitudinal axis perpendicular to the build platform (parallel to the build direction/Z axis). The rectangular specimens have their longitudinal axis perpendicular to the build direction/Z axis. In this study, the 
terms vertical orientation and horizontal orientation are used to identify samples that are oriented parallel and perpendicular to the build direction/Z axis respectively. For this body of work only the vertical oriented cylindrical samples were used, from which cylindrical tensile specimens (Figure 4) were machined. Metallographic analysis and micro-hardness measurements were also carried out on these samples.

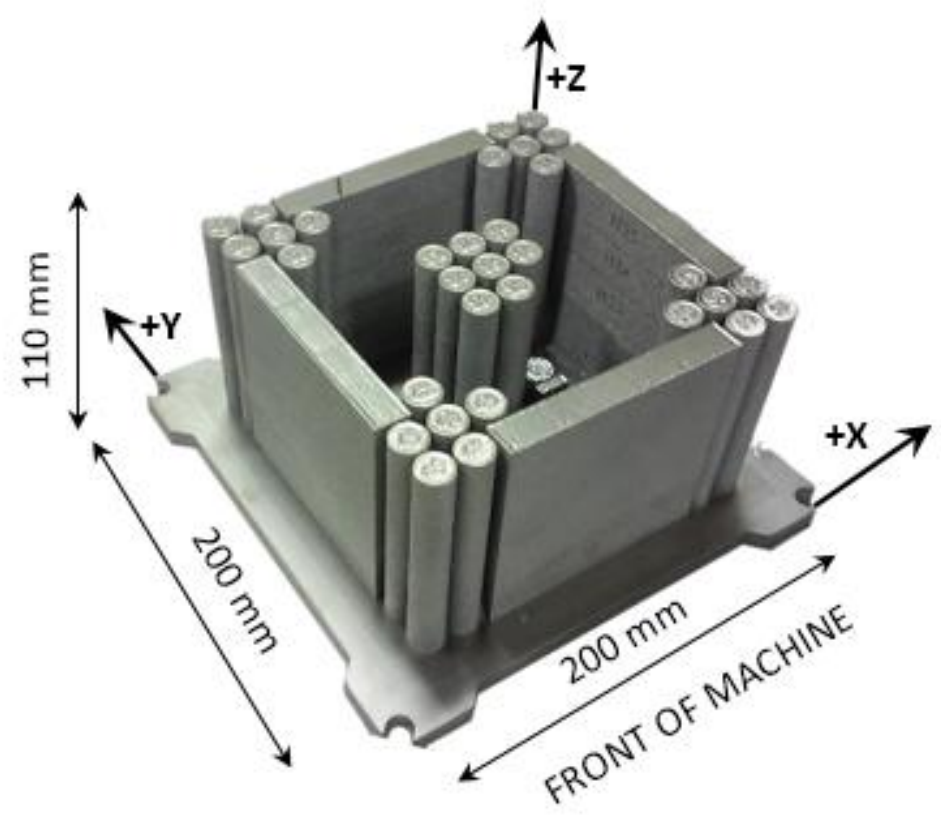

Figure 2. Layout of the specimens on the build platform with the standard AM axis system [25].

\subsection{Characterization methodology}

\subsubsection{Microstructure characterization}

All metallographic samples were cut with an abrasive wheel, mechanically ground and polished, and etched with Kroll's reagent following the preparation process for titanium alloys laid out in Buehler SumMet 2013 [26]. Microstructures were characterized using standard metallographic methods with a Nikon MA 200 Eclipse microscope and image analysis using Elements-D software.

The $\alpha$ lath thickness, or interlamellar spacing, which is representative of typical $\alpha+\beta$ titanium microstructures, was measured using the method recommended by Vander Voort et al. [27] which was successfully used in a previous study [21]. The procedure consists of calculating the mean random spacing, $\sigma_{r}$, using the intersection method. The intersection method is performed by overlaying a test grid consisting of one circle of known radius, $R$, on the micrograph in an unbiased manner as shown in Figure 3. The number of intersections of the $\alpha$ lamellae with the test line, $M$, are counted and divided by the actual length of the test line, to obtain $N_{L}=2 \pi R / M$. The reciprocal of $N_{L}$ is the mean random spacing: $\sigma_{r}=1 / N_{L}$. The mean true spacing, $\sigma_{t}$, is calculated dividing the mean random spacing by two: $\sigma_{t}=\sigma_{r} / 2$. This methodology was applied for five images in each location and the values were averaged to determine the interlamellar spacing at each location. 


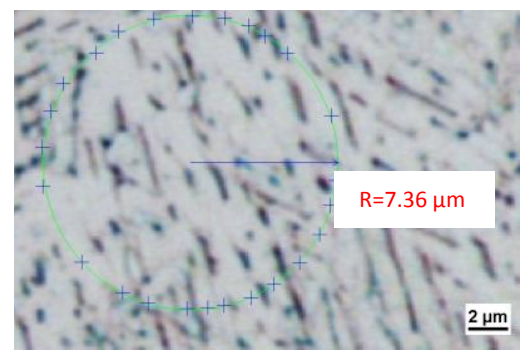

Figure 3. Intersection of $\alpha$ laths on a $7.36 \mu$ m radius circle measured with the image analysis software. The image was obtained in the optical microscope at 1000x magnification and digitally zoomed [21].

Phase analysis was performed using a Panalytical Empyrean 2 X-Ray Diffractometer (Panalytical B.V., Almelo, Netherlands) using CuK $\alpha$ radiation at $40 \mathrm{keV}$ and $40 \mathrm{~mA}$ from 30 to 150 degrees of $2 \theta$. It should be noted that texture and strain are present in these samples, so the XRD results are present for qualitative comparison rather than quantitative phase fraction purposes.

\subsubsection{Microhardness and tensile testing}

Microhardness indentation measurements were made using a TUKON 1202 (Wilson Hardness) machine, with a load of $10 \mathrm{~N}$ applied for 10 seconds. The values reported in this study are each average values of 15 individual microhardness measurements conducted in accordance with ASTM E384 [28].

Round tensile specimens were machined using a HAAS CNC mill and lathe, with a final length of $100 \mathrm{~mm}$, gauge diameter of $6 \mathrm{~mm}$, and gauge length of $25 \mathrm{~mm}$, Figure 4 . The geometry and dimensions of the tensile specimens, as well as the room temperature tensile tests, were performed following ASTM-E8M [29] specifications, using an Instron 5500R test frame.

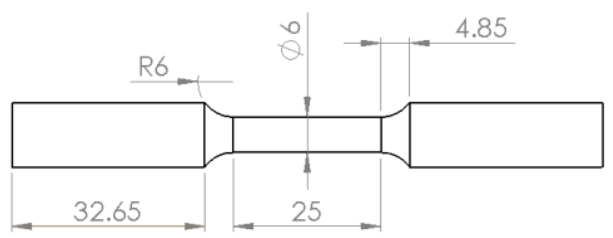

(a)

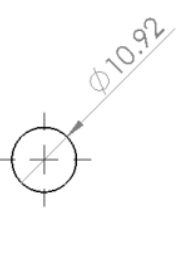

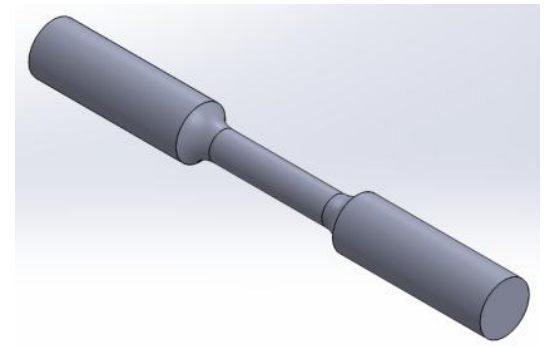

(b)

Figure 4. (a) Manufacturing drawing, and (b) computer model of the round bar tensile specimens used for this body for work. Drawings are not to scale, all units are in $\mathrm{mm}$ 


\section{Results and discussion}

\subsection{Thermal analysis of the EBM process}

\subsubsection{Thermal history}

The relevant thermal events that determine the as-fabricated microstructure in the EBM process can be simplified in three main stages [30]. First step is a rapid cooling from the molten state to the layer temperature, followed by a quasi-isothermal stage at the local temperature until completion of the build, and finishing with a slow cooling to room temperature, Figure 5.

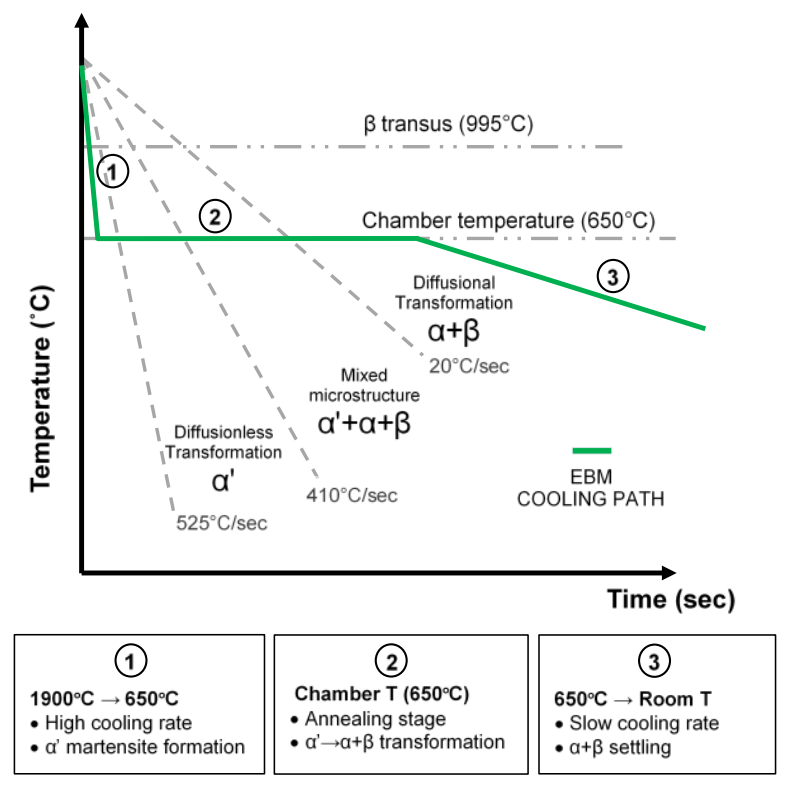

Figure 5. Cooling path and critical cooling rates for Ti-6Al-4V microstructure formation in EBM process with a chamber temperature of $650^{\circ} \mathrm{C}$. Microstructural transformations occurring in each stage are also shown.

The first stage comprises the cooling of the melt pool, solidification of the melt, and cooling to the chamber temperature. The melt pool temperature values are estimated to be between $1900^{\circ} \mathrm{C}$ and $2700^{\circ} \mathrm{C}[30,31]$. One particular study made by thermography measured a temperature of $2500^{\circ} \mathrm{C}$ on the melt pool [32]. The most critical cooling stage for the formation of the microstructure is the cooling period from the solidification temperature (around $1900^{\circ} \mathrm{C}$ ) to the chamber temperature because $\beta$ grains formation, as well as subsequent transformation of $\beta$ phase, occur at temperatures above $870^{\circ} \mathrm{C}$ [9]. In this stage, a diffusionless transformation occurs because the cooling rate is higher than the critical martensitic transformation cooling rate estimated as $410 \mathrm{~K} / \mathrm{sec}$, and therefore $\alpha^{\prime}$ martensite phase is formed. The cooling rate in this stage has been calculated to be in the range of $10^{3}$ to $10^{5} \mathrm{~K} / \mathrm{sec}$ [33].

The second stage consists of a dwell at the fabrication chamber temperature, until all the layers that comprise the build are finished, usually at $650-750^{\circ} \mathrm{C}$. In this period, the $\alpha^{\prime}$ martensite is transformed into an $\alpha+\beta$ structure $[21,30]$. This is considered a quasi-steady state, where the temperature varies gradually due to the heat transfer between the above layer melt pools and the rest of the manufacturing part. The high temperature of the chamber $\left(650-750^{\circ} \mathrm{C}\right)$ and complex re-melting and re-heating periods transform the $\alpha^{\prime}$ martensitic phase into the more stable $\alpha+\beta$ microstructure $[17,21]$. The third stage comprises the slow cooling of the build from the chamber temperature to room temperature. 
These three stages are the main stages that determine the resultant microstructure in the EBM process. However, in reality the thermal history of a given point in the build, has a much more complex history due to the influence of the upper layer melting pools, and reheating or partially re-melting the material to a greater or lesser degree, depending on the scanning parameters such as beam power, scanning velocity, and spot size [30,34]. The next step in developing a better appreciation of the phase transformations during the EBM process, and in order to obtain an understanding of the subsequent microstructural changes occurring during the heat treatments, a study of the thermal history in the EBM process was performed by developing a thermal simulation of the fabrication process.

\subsubsection{Thermal simulation}

A thermal simulation was performed in order to attain a better understanding of the complex thermal history during the EBM process. ANSYS Workbench R15.0 software was employed for this task. The simulation was accomplished for a beam scan on a $10 \times 10 \times 10 \mathrm{~mm}^{3}$ cube, Figure 6 a. The path of the electron beam during the scanning of the layers is comprised typically by two main scanning strategies: the first strategy named contouring, melts the outline of each 2D section; the second, called hatching 'fills in' the outline by rastering the beam within the section boundary. The contouring strategy uses a technology known as MultiBeam, which rapidly moves the beam so as to keep several separate melt pools active at one time. As a result of the MultiBeam settings, 50 melt pools are present during the outer contour and 10 during the inner contours. The center of each section is then 'filled in' by rastering the beam in a 'snaking' melt strategy known as hatching (i.e., a forward and backward beam motion with a continuous path). The hatching direction is rotated a certain angle between each layer. The beam current during hatching is not directly set by the operator, instead, it is calculated by the EBM control software and varied linearly with the length of the hatch line, such that smaller melt lengths have a lower current [22].

The goal of this simulation was to demonstrate the complexity of the thermal history of the EBM process compared to the "three-stage" simplified model described before, considering that the real process is even more complex than that obtained by this simulation. The scanning process for the simulation was simplified considerably, having one contouring and three lines of hatch for each melting stage (Figure 6a). By performing the contouring and the hatch melting stages an approximation of how the scanning steps influence the temperatures in the consecutive layers was obtained. The electron beam movement simulation was performed assigning a time dependent energy input on the surface of the cube in such a way that it follows the scanning path. The value of the energy input (200W for each $2 \times 2 \mathrm{~mm}^{2}$ segment) was adjusted in order to get melt pool dimensions and temperatures consistent with previous works. [28-30, 35]

The following boundary conditions were considered for the simulation:

- Radiation heat transfer for the top surface (emissivity value: $\varepsilon=0.26$ ) [27].

- Constant temperature for the bottom of the cube (build platform temperature: $T=650^{\circ} \mathrm{C}$ )

- Conduction heat transfer in the cube (temperature dependent conductivity, density, and specific heat) [23].

- Heat transfer between the solid cube and the powder was considered as temperature and surface dependent, and directly proportional to a heat transfer coefficient $\left(5 \times 10^{4} \mathrm{~W} /\left(\mathrm{m}^{2} \mathrm{~K}\right)\right)$. 


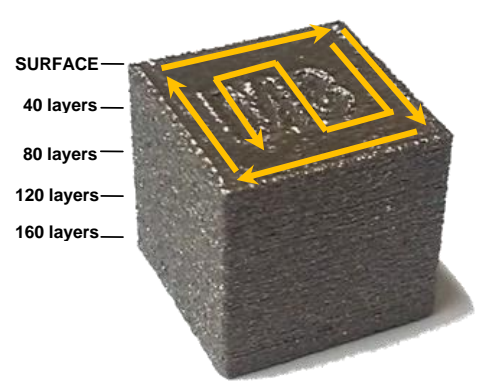

(a)

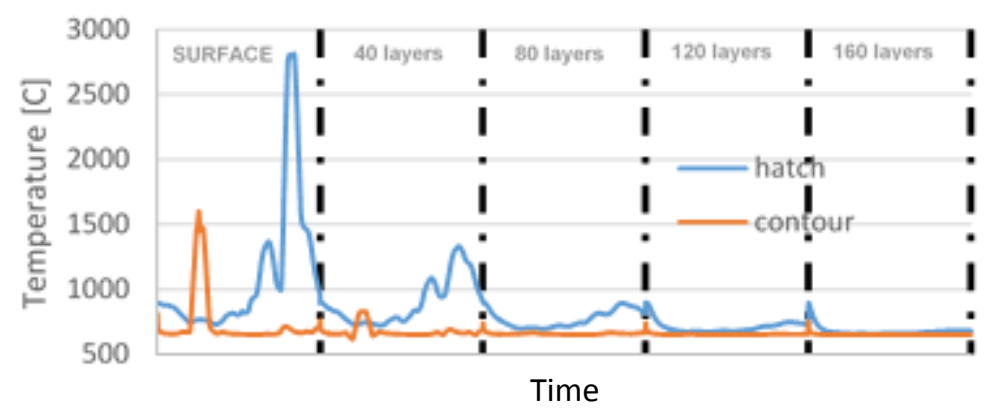

(b)

Figure 6. (a) Scanning path of the electron beam for the thermal modeling. (b) Temperature evolution during scanning stage on the surface. The temperature evolution of locations on the hatch area and on the contour zone is shown for the surface and four layers at different depths.

The graphical result of the transient thermal simulation is shown in Figure 7. In the cross section of the cube (Figure 7b) it is possible to see how the melt pool (red) penetrates inside the cube. A heat-affected zone (orange) has been considered for the areas above the $\beta$ transus temperature $\left(1000^{\circ} \mathrm{C}\right)$.

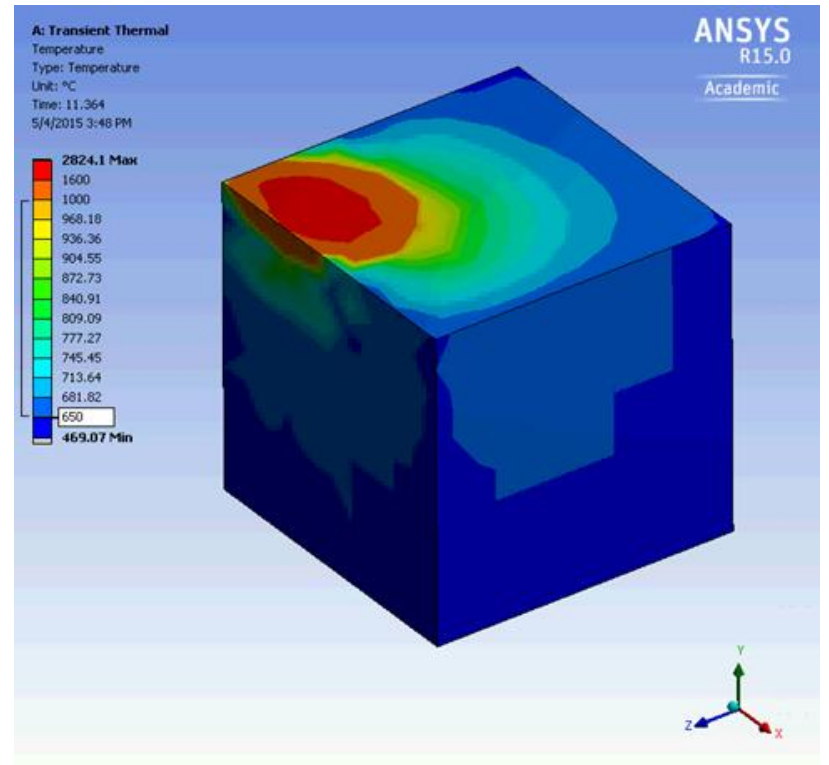

(a)

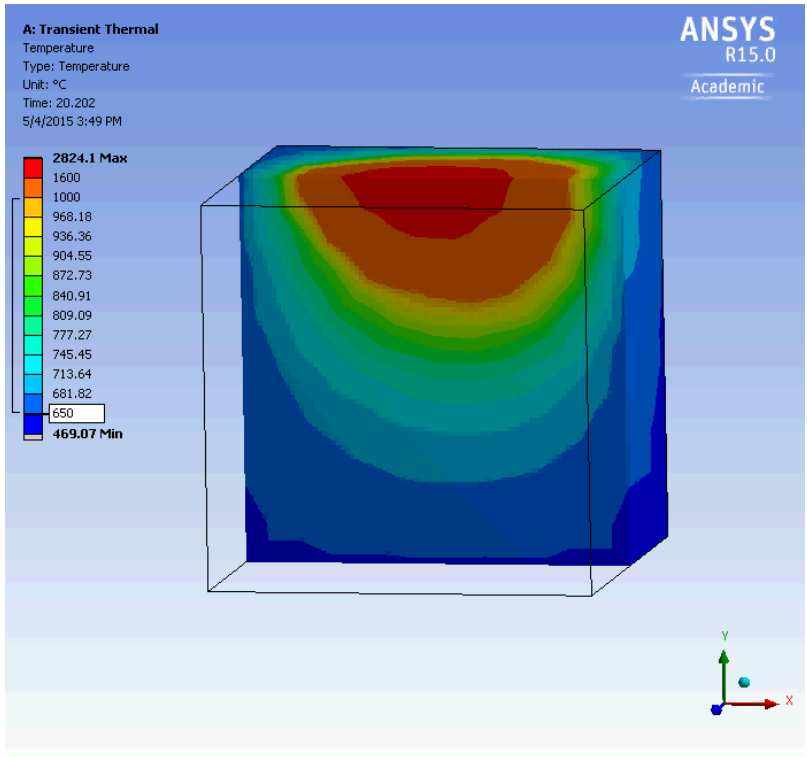

(b)

Figure 7. Screenshot of the EBM process simulation: (a) entire part during the contouring strategy and (b) cross-section during the hatching strategy.

As predicted, the effect of the electron beam during the scanning of the surface varies with the depth of the layers below (Figure 6b), making the thermal history significantly more complex than that considered in the simplified thermal history. According to the simulation, the melt pool can affect the first 10-20 scanning layers, and due to the heat transfer to the solid part, the cooling rates of the melt pool can reach $2000^{\circ} \mathrm{C} / \mathrm{sec}$. 


\subsection{As-fabricated microstructure and properties}

Microstructures and mechanical properties of the heat-treated parts were compared to those in the asfabricated condition. Reference values for the as-fabricated condition were obtained from a previous study reported by this team, where microstructure and mechanical properties were thoroughly characterized and discussed [21]. The microstructure is comprised of prior $\beta$ columnar grains oriented parallel to the build direction (Z or vertical axis), Figure 8a. An $\alpha+\beta$ lamellar microstructure is observed inside the prior $\beta$ grains for planes both perpendicular and parallel to the build direction. The structure of the lamellae is mainly Widmanstätten or "basket weave", with an occasional colony microstructure. The size of the columnar grains is not quantifiable due to the difficulty of grain boundary identification. In several instances, the $\alpha$ layer at the prior $\beta$ grain boundaries could be seen, Figure $8 \mathrm{~b}$, and average thickness of $2 \mu \mathrm{m}$ was measured. Figure 9 shows the XRD pattern obtained from a Ti-6Al-4V ELI sample, where only $\alpha$ and $\beta$ peaks have been detected, confirming the $\alpha+\beta$ microstructure observed also by microscopy.

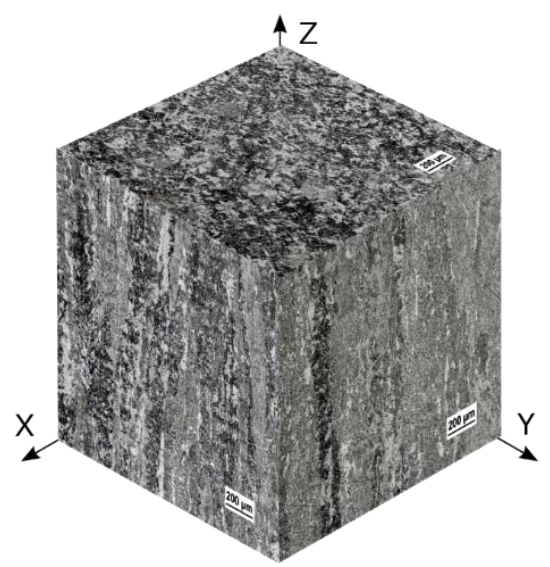

(a)

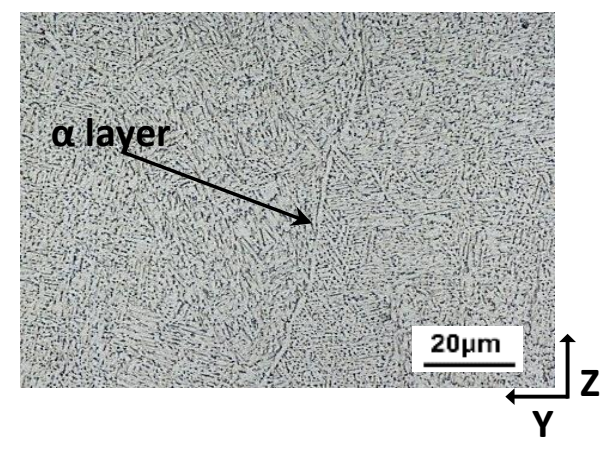

(b)

Figure 8. (a) 3D microstructural cube (Z axis represents the build direction). (b) YZ plane microstructure (parallel to the build direction). Basket weave and colony pattern $\alpha+\beta$ lamellar structure can be observed in columnar arrangement divided by $\alpha$ phase layer at the prior 8 grain boundaries [21].

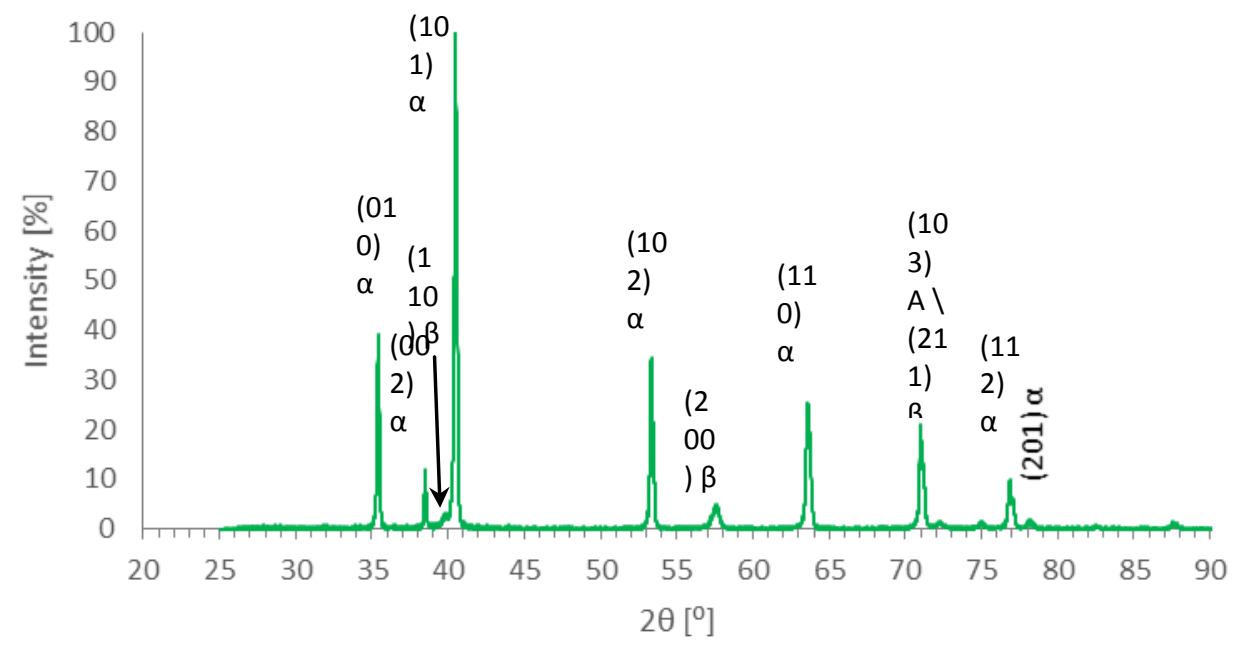

Figure 9. XRD pattern for the EBM build Ti-6AI-4V ELI sample, indicating $\alpha+6$ phases. 
The reference values of the $\alpha$ lath thickness, tensile properties, and micro-hardness for the as-fabricated condition employed in this study are as follows:

- $\quad \alpha$ lath thickness: $1.4 \mu \mathrm{m}$

- UTS=1073 MPa ( $\pm 45 \mathrm{MPa})$

- $\mathrm{YS}=1001 \mathrm{MPa} \quad( \pm 42 \mathrm{MPa})$

- $\mathrm{el}=11 \% \quad( \pm 1 \%)$

- Hardness: $366 \mathrm{HV} \quad( \pm 5 \mathrm{HV})$

While it would be ideal to use AM produced components in their as-fabricated state, the use of various heat treatments can change the mechanical properties to suit the required application. The effects of solution heat treatments, cooling rates, and aging heat treatments are thus examined in the following sections.

\subsection{Effects of the cooling rate}

\subsubsection{Effects on microstructure and mechanical properties}

The time and temperature of the heat treatment, as well the cooling rate, are the critical factors affecting the final microstructure [34]. In this study, a solutionizing treatment was first applied at $1100^{\circ} \mathrm{C}$ for 30 minutes. This temperature is $105^{\circ} \mathrm{C}$ above to $\beta$ transus temperature of the alloy (which is around $995^{\circ} \mathrm{C}$ ), ensuring that at the solutionizing temperature the microstructure of the sample is $100 \% \beta$ phase. Then, with the purpose of studying the effect of cooling rate from temperatures above $\beta$ transus on the resultant microstructure and properties; furnace-cooling, air-cooling, and water-cooling were performed. The cooling rate from temperatures above the $\beta$ transus can control the formation of different microstructures as shown in the continuous cooling transformation (CCT) diagram, Figure 10. Furnacecooling was measured reading the values of the furnace chamber temperature on the display. The cooling rate of the air-cooling stage was measured with a thermocouple inserted in a hole drilled in the center of the sample. The measured average air-cooling rate from $1100^{\circ} \mathrm{C}$ to $500^{\circ} \mathrm{C}$ was about $20^{\circ} \mathrm{C} / \mathrm{sec}$ which may result in formation of a small volume fraction of $\alpha^{\prime}$ martensite along with the $\alpha$ phase and in addition to the previously existing $\beta$ phase. The water-cooling rate was estimated to be $650^{\circ} \mathrm{C} / \mathrm{sec}$.

The results of this study are shown in Table 2. The first and second rows show the microstructures at 100x and 500x magnifications. On the last row, mechanical properties and micro-hardness values are reported. The analysis of the results reveal the changes in the microstructure and properties of the heattreated samples due to different cooling rates compared to the as-fabricated condition. The increase in tensile strength and micro-hardness with increasing cooling rate is evident. Ductility, however, decreases considerably because of solutionizing above the $\beta$ transus temperature. This causes the morphology of the $\beta$ grains to change from columnar to equiaxed. 


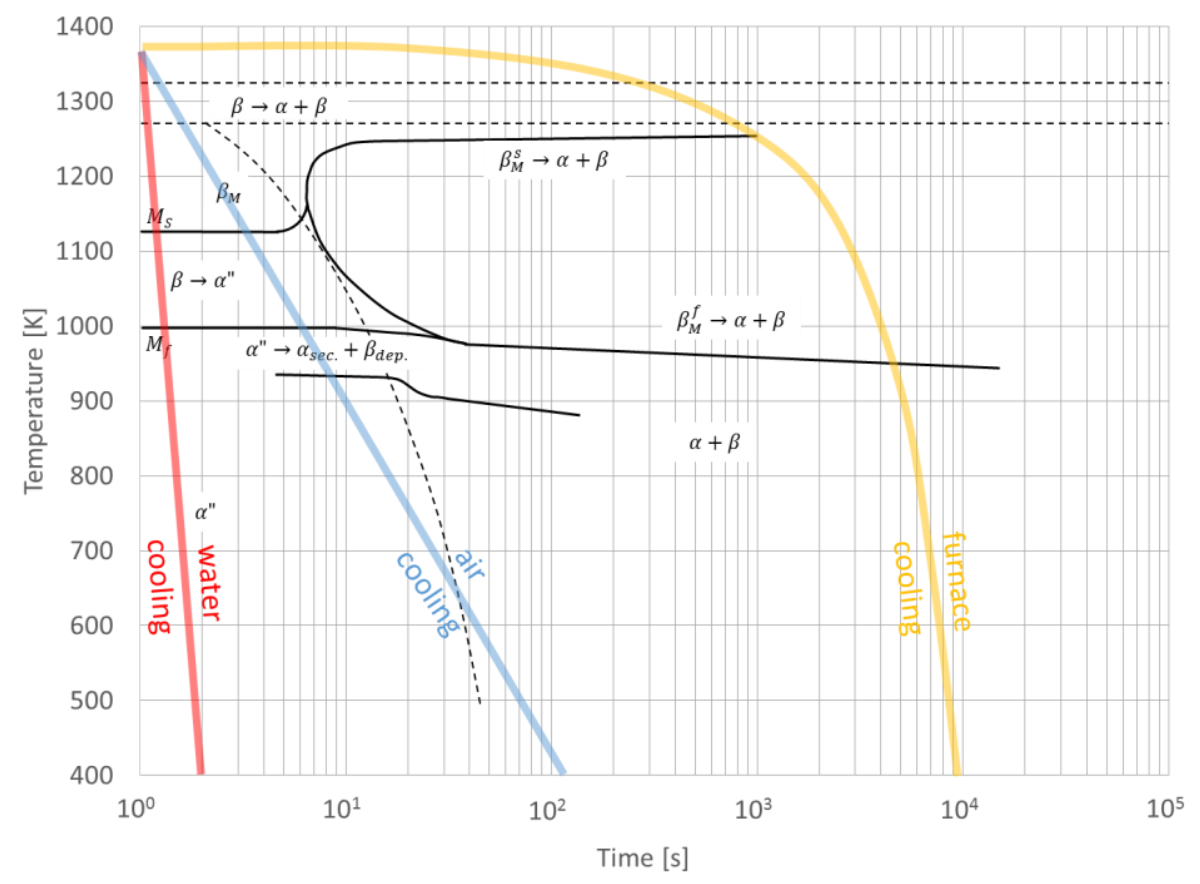

Figure 10. CCT diagram for Ti-6Al-4V (adapted from ref. [37]). Cooling curves of three different cooling methods (furnace, air, and water cooling) employed in this work are plotted, showing the microstructural transformation associated with each method.

Table 2. Cooling rate study results for furnace, air, and water cooled conditions

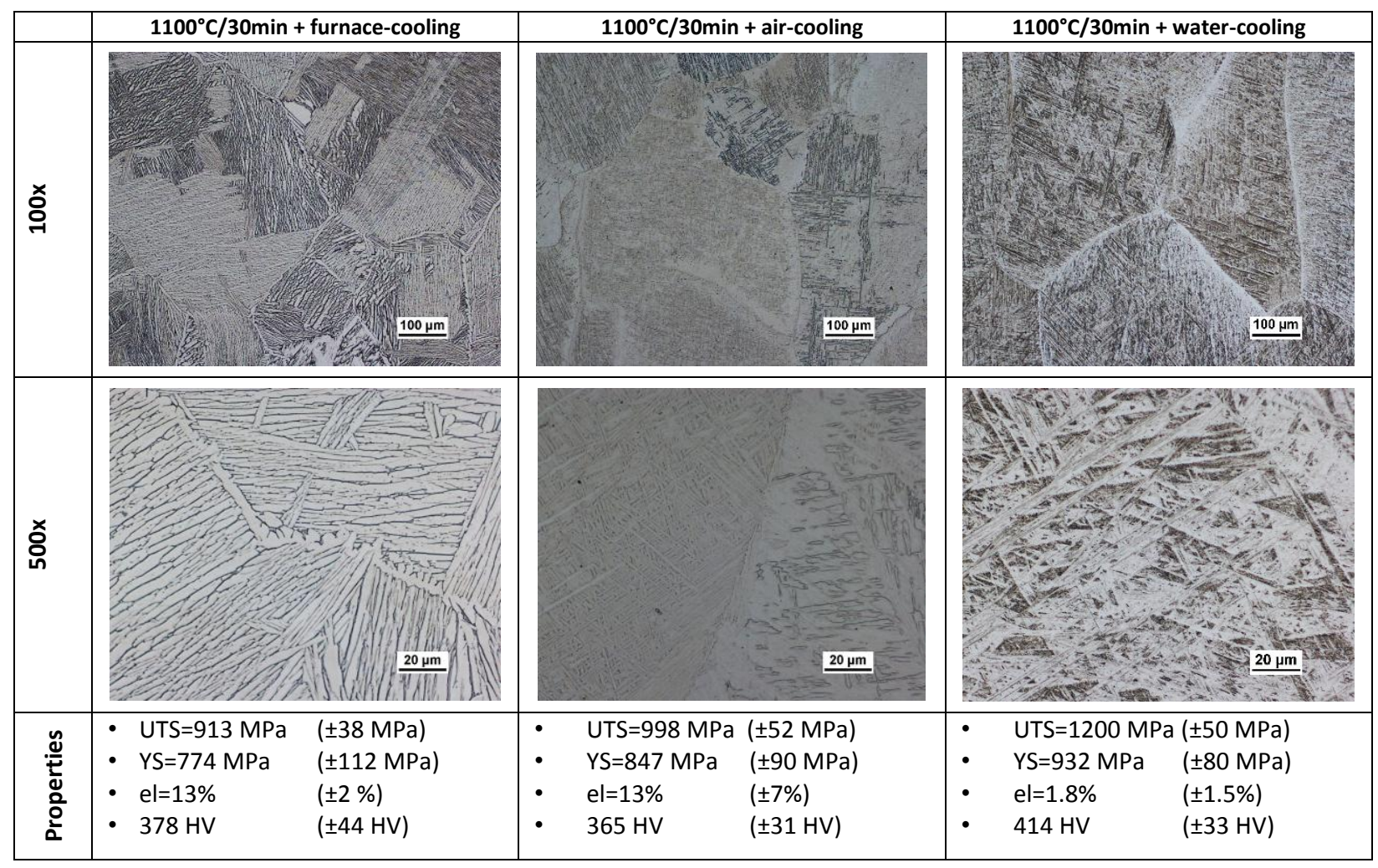


The study of XRD diffraction patterns for as-fabricated, air-cooled, and water-cooled conditions, Figure 11 , shows a weakening and an absence of a diffraction peak at the $2 \theta=57^{\circ}$ position (denoted by the black circle in Figure 11) in the air-cooled and water-cooled conditions respectively. This peak corresponds to the $\beta$ phase (200) plane diffraction peak. This fact, along with the visual analysis of the microstructure, tensile test results, and micro-hardness values indicate that the air-cooled condition contains $\alpha^{\prime}$ martensitic phase at some extent while the water-cooled condition contains a fully martensitic microstructure.

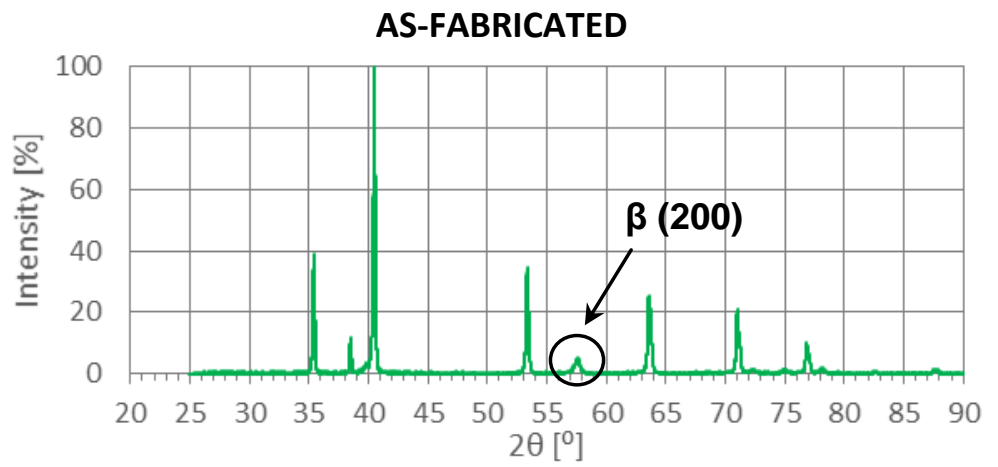

AIR-COOLED

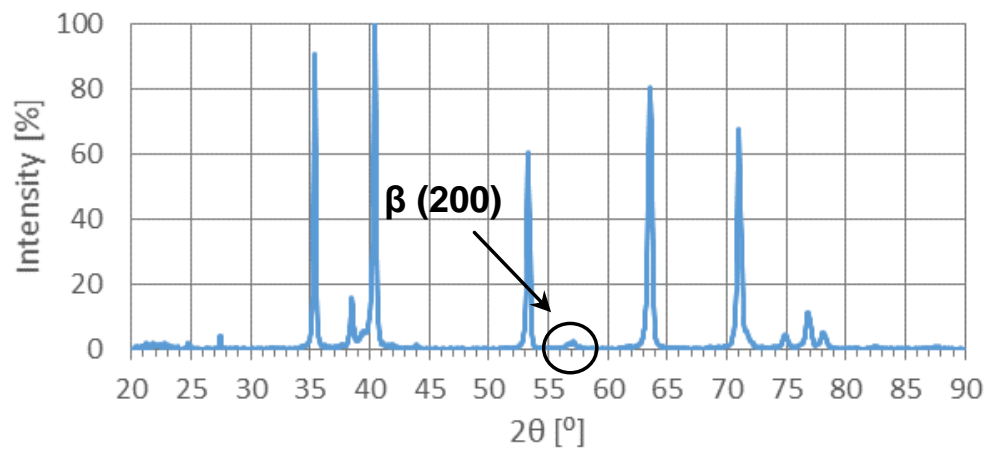

WATER-COOLED

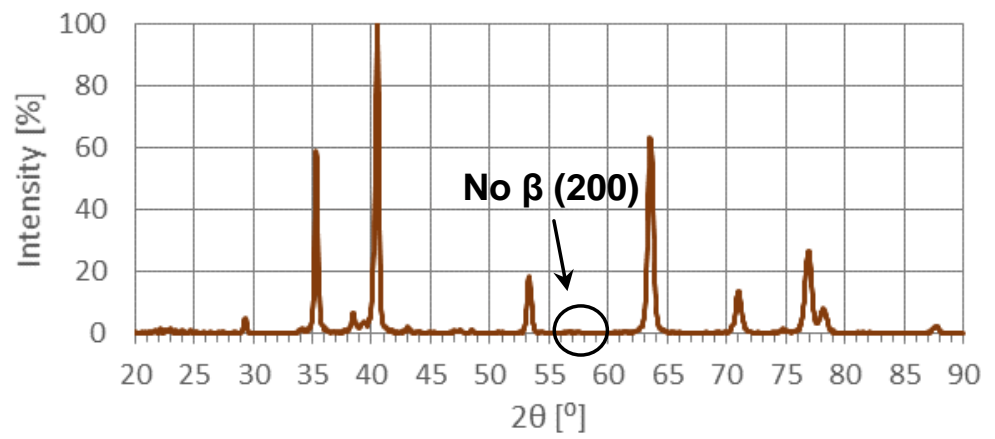

Figure 11. XRD diffraction patterns obtained with $K_{C U \alpha}$ for as-fabricated, air-cooled, and water-cooled conditions.

The values for the UTS, YS, and \% elongation have been plotted for each type of microstructure obtained in this study, Figure 12. The graph shows that the columnar microstructure of the as-fabricated condition has a higher strength than the equiaxed $(\alpha+\beta)$ structure of the furnace-cooled condition. The $\alpha^{\prime}$ martensite phase also has a strengthening effect, however the ductility of the alloy decreases dramatically as the amount of $\alpha^{\prime}$ increases. The evolution of the hardness is also similar to that of the 
UTS, with the lowest hardness value corresponding to the equiaxed $\alpha+\beta$, and the highest to the fully $\alpha^{\prime}$ martensitic microstructure. The hardness of the as-fabricated, columnar $\alpha+\beta$ structure is similar to the partially martensitic, air-cooled condition.

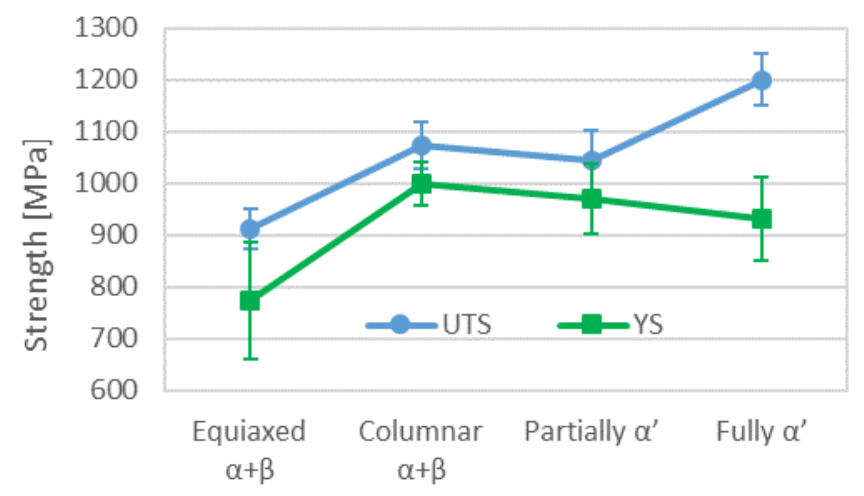

(a)

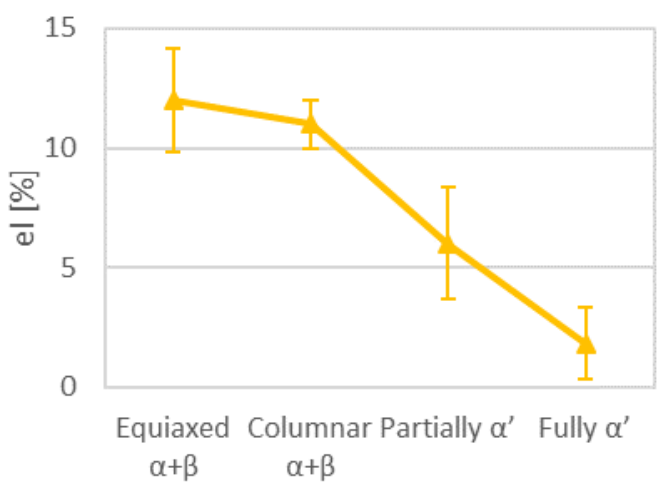

(b)

Figure 12. (a) Ultimate strength and Yield strength and (b) \% elongation values for the microstructures obtained after different cooling rates. Equiaxed $\alpha+\beta$ corresponds to furnace-cooling condition, columnar $\alpha+\beta$ corresponds to as-fabricated condition, partially $\alpha^{\prime}$ corresponds to air-cooled condition, and fully $\alpha^{\prime}$ corresponds to water-cooled condition.

\subsubsection{Effects on microstructure and mechanical properties after subsequent aging}

The desired strength of $\alpha+\beta$ titanium alloys is achieved by solution heat treatment followed by different aging treatments. Titanium alloys have two dominant hardening mechanisms: solid solution hardening and precipitation hardening. The type of heat treatment dictates which of these two becomes the dominant hardening mechanism. On slow cooling from $\beta$ phase, the $\alpha$ phase is hardened by solid solution hardening via partitioning of $\mathrm{Al}$ and $\mathrm{O}$ elements in $\alpha$ phase. On the other hand, long term aging at circa $500^{\circ} \mathrm{C}$ results in precipitation hardening of the $\alpha$ phase via precipitation of $\mathrm{Ti}_{3} \mathrm{Al}$. Quenching from the $\beta$ phase field results in formation of martensite with high dislocation density, which results in hardening via dislocation strengthening [38-40]. Considering the effect that this heat treatment would have on the EBM Ti-6Al-4V ELI alloy, two solution and aging treatments have been performed comparing the effect of the cooling rate after solutionizing at $925^{\circ} \mathrm{C}$ for one hour, followed by aging at $450^{\circ} \mathrm{C}$ for 4 hours. The solutionizing was carried out at $925^{\circ} \mathrm{C}$ in order to maintain the columnar structure from the as-fabricated condition, while understanding the effect of aging schedules. The resulting microstructures and mechanical properties from the solutionizing + aging studies are shown in Table 3.

From the results, a considerable increase in the ultimate tensile strength was observed for the watercooled samples compared to the air-cooled samples. Significant variation in elongation was observed in these tests, which is mostly attributed to a heterogeneous distribution of porosity. Water-cooling was proven as an appropriate way to obtain the expected strengthening effect. The higher UTS for the water-cooled condition is due to change in phase fraction as a function of temperature as shown in Figure 13. Simulations using Thermocalc ${ }^{\circledR}$ show that at a temperature of $925^{\circ} \mathrm{C}$ the microstructure is approximately $97 \% \beta$ phase. Water-cooling from this condition results in formation of $\alpha^{\prime}$ martensite needles, which are visible in the micrograph in the top row of Table 3. The $\alpha^{\prime}$ phase is responsible for the higher strength and reduced ductility of the water-cooled condition, and subsequent aging at $450^{\circ} \mathrm{C}$ for 4 hours does not result in decomposition of martensite into $\alpha$ phase due to sluggish transformation kinetics. In order to recover some of the lost elongation, and achieve a favorable balance between 
ductility and strength, an additional study was performed focusing on the aging effects. Aging studies were performed on both as-fabricated $\alpha+\beta$ Ti-6Al-4V and previously solution heat treated materials, as discussed in Section 3.3.

Table 3. Solution + aging treatments and results

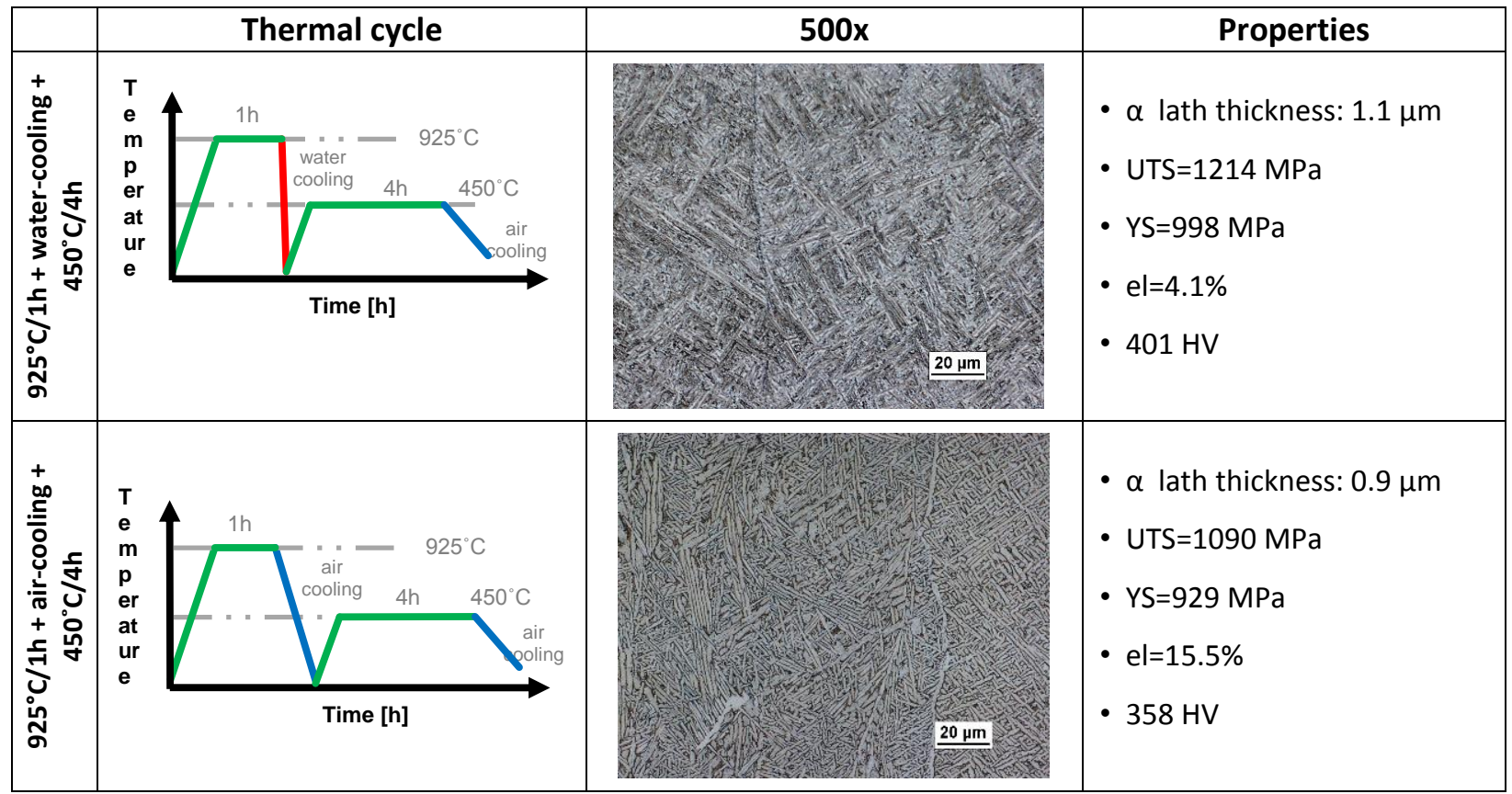

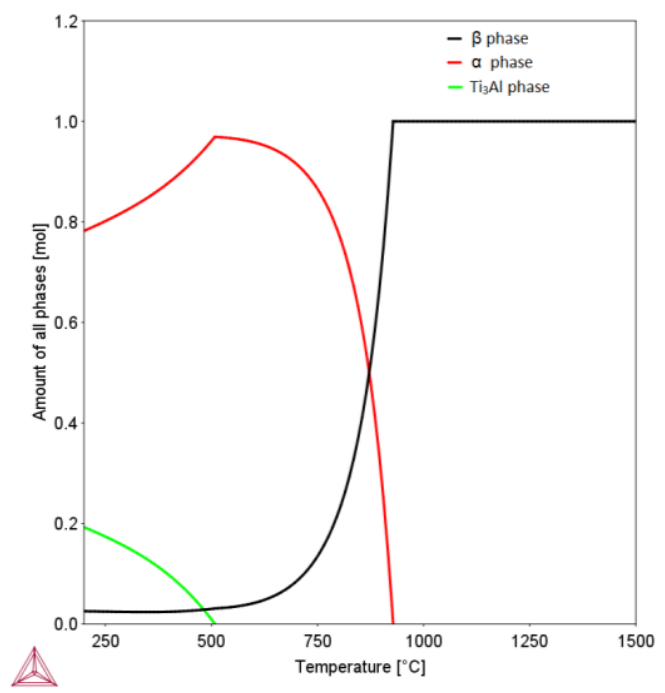

Figure 13. $\alpha, 6$ and $\mathrm{Ti}_{3} \mathrm{Al}$ equilibrium phase fraction for Ti-6Al-4V at different temperatures obtained from Thermocalc ${ }^{\circledR}$.

\subsection{Effects of aging time and temperature}

The mechanical properties of $\alpha+\beta$ titanium alloys are strongly dependent on the morphology and distribution of the $\alpha$ phase. In the case of alloys with a lamellar microstructure, the thickness of the $\alpha$ lamellae and the diameter of their colonies has been shown to have the most significant effect on 
mechanical properties [9]. Vrancken at al. studied the influence of aging time and temperature for SLM Ti-6Al-4V and underlined that the $\alpha$ lath thickness is dependent on the aging temperature [41].

In a previous iteration of this work which investigated the microstructure of EBM Ti-6Al-4V ELI, it was found that aging the material resulted in a coarsening of the $\alpha$ lath within the microstructure [21]. In that study, a systematic understanding of the effects of aging time on the coarsening of the $\alpha$ lath thickness was obtained by examining specimens from the same area of a build that had subsequently been annealed for different times at $600^{\circ} \mathrm{C}, 700^{\circ} \mathrm{C}$, and $800^{\circ} \mathrm{C}$, as shown in Figure 14 . In order to expand on the original work in the context of the current study, an additional set of aging experiments was conducted at $900^{\circ} \mathrm{C}$.

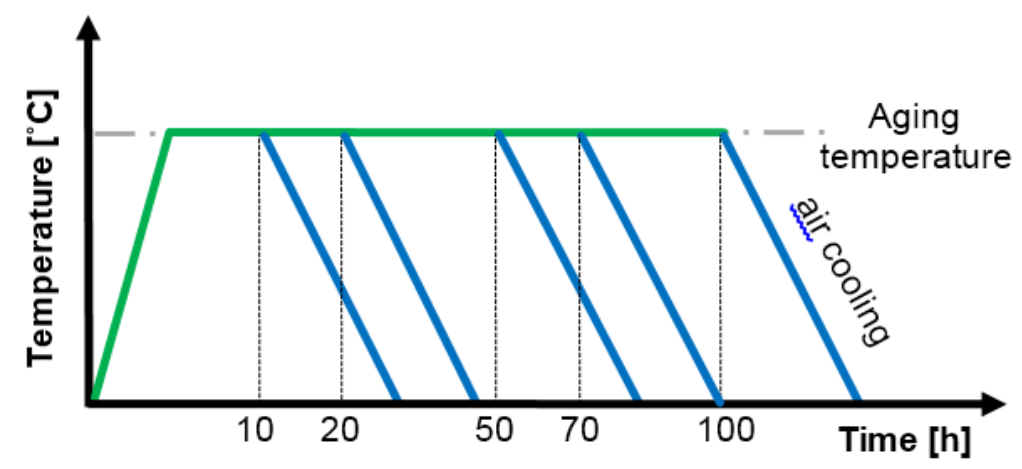

Figure 14. Temperature-time diagram for the aging studies.

Selected microstructures and hardness values obtained from the aging studies are shown in Figure 15. Micrographs show slightly coarser microstructures for the samples annealed at $700^{\circ} \mathrm{C}$ for 100 hours, Figure 15b, than those of the as-fabricated condition, Figure 15a. The visual data were confirmed by the measuring of the $\alpha$ lath thickness with image analysis software, where a coarsening from $0.66 \mu \mathrm{m}$ to $1.03 \mu \mathrm{m}$ was observed. The micro-hardness differences between the two conditions, however, are not significant (369 HV versus $364 \mathrm{HV}$ ). As aging temperature was increased, the coarsening of the $\alpha$ lath also increased as shown in Figure $15 \mathrm{c}$ and $15 \mathrm{~d}$, corresponding to the results for the aging treatments at $900^{\circ} \mathrm{C}$ for 20 hours and 70 hours. At this temperature, some effects can also be noticed in microhardness. In contrast to the post-solutionizing microstructure studied in the previous section, the microstructures of the annealed parts still retain the columnar morphology. 


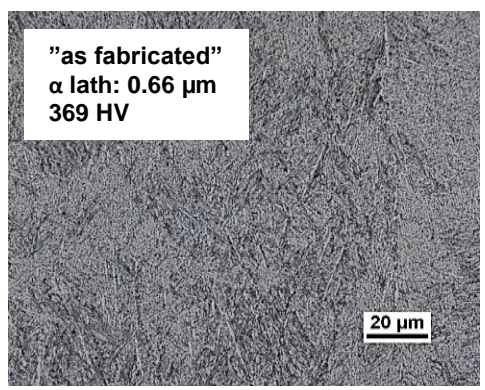

(a)

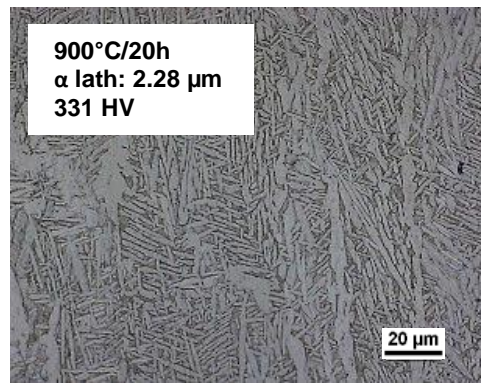

(c)

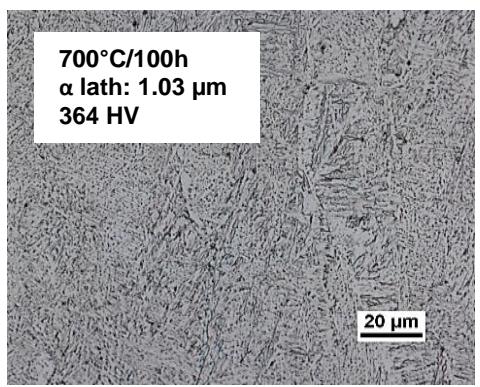

(b)

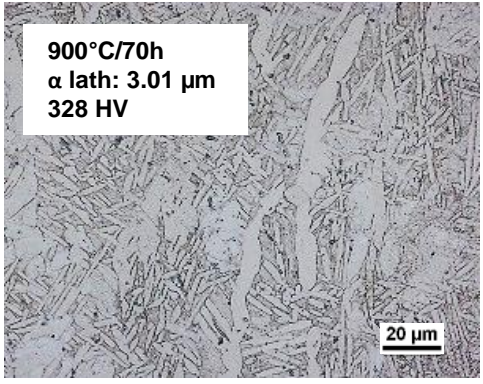

(d)

Figure 15. Micrographs at 500x magnification for (a) as-fabricated, (b) annealed at $700^{\circ} \mathrm{C}$ for 100 hours, (c) annealed at $900^{\circ} \mathrm{C}$ for 20 hours, (d) annealed at $900^{\circ} \mathrm{C}$ for 70 hours.

The results of the $\alpha$ lath thickness measurement for all the aging temperatures and times are plotted in Figure 16. The graph shows that $\alpha$ lath grows with temperature and time. This phenomenon explains the $\alpha$ lath thickness variation with the distance from the EBM build platform studied in a previous work [21]. The microstructure of the layers closer to the build platform have been at the chamber temperature for a longer time than the layers further away, so the $\alpha$ lath thickness is larger at locations closer to the build platform. The effect of the aging time and temperature on the $\alpha$ lath thickness has been correlated with the following equation which was developed in a previous study [21]:

$$
\delta_{\alpha_{\text {lath }}}=\delta_{\alpha_{\text {lath }}(t=0)} \cdot t^{\left(\frac{T-850}{1000}\right)}
$$

where, $\delta_{\alpha_{\text {lath }}}$ is $\alpha$ lath thickness in $\mu \mathrm{m}, \delta_{\alpha_{\text {lath }}(t=0)}$ is $\alpha$ lath thickness of the starting material in $\mu \mathrm{m}, t$ is the aging time in hours, and $T$ is the aging temperature in $\mathrm{K}$. The calculated values using this equation have been plotted along with the measured values in Figure 16 to evaluate the effectiveness of the calculations using Eq. (1). 


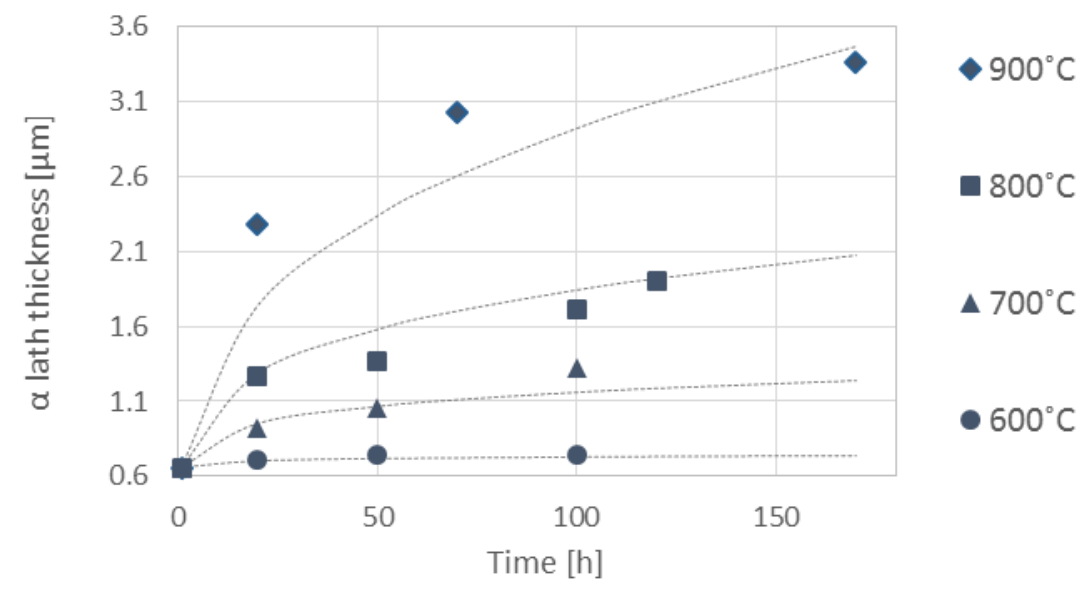

Figure 16. Experimental data of $\alpha$ lath thickness versus aging time graph for different temperatures. Dotted lines represent the values calculated using Eq. (1) [25]; additional data at $900^{\circ} \mathrm{C}$ have been added to the original work.

Next, the relationship between $\alpha$ lath thickness and micro-hardness and tensile properties have been addressed. Micro-hardness values have been measured for the samples annealed at different time and temperature combinations, and are plotted for the corresponding $\alpha$ lath thicknesses, Figure 17. In this plot, values from a previous study [9] were also added, and a relationship between $\alpha$ lath thickness and micro-hardness was observed.

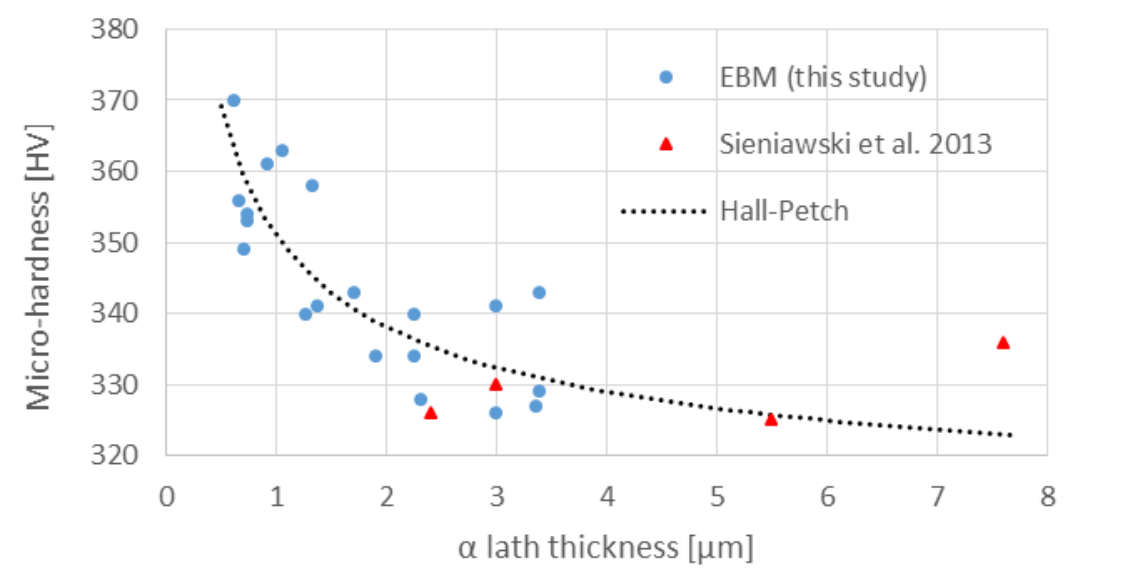

Figure 17. Experimental micro-hardness measurements for different $\alpha$ lath thickness values including values reported by Sieniawski et al. [9]. Dotted lines represent the values calculated using Eq. (3).

The effect of the $\alpha$ lath thickness on the mechanical properties can be explained following the dislocation theory assuming that microstructural features act as obstacles to dislocation slip, causing dislocation pile-ups. In coarse grained materials, the stress multiplication caused by the dislocation pileups is much greater than in fine-grained materials. The empirical relation between microstructural size and mechanical properties such as hardness and yield stress can be written by a Hall-Petch type equation [42], using $\alpha$ lath thickness:

$$
H=H_{0}+k_{H} \delta_{\alpha_{\text {lath }}}^{-1 / 2}
$$


where, $H$ can be either hardness or yield stress, $\delta_{\alpha_{\text {lat }} \text { in }}$ is the $\alpha$ lath thickness, and $k_{H}$ and $H_{O}$ are constants. Traditionally, the microstructural size for $\alpha+\beta$ titanium alloys has been related to the grain size or colony size. In this study, $\alpha$ lath thickness was considered as the relevant microstructural characteristic dimension, following a previous work where Hall-Petch equation was proposed for lamellar structured steels [43]. A Hall-Petch type equation was previously suggested for hardness and yield strength of EBM Ti-6Al-4V by Jamshidinia et al. [44]. The empirical relation between $\alpha$ lath thickness and hardness values obtained in this study, as well as values shown by other authors [12], Figure 17, was modeled with the following equation:

$$
H V=307+44 \delta_{\alpha_{\text {lath }}^{-1 / 2}}^{-1 / 2}
$$

where, $H V$ is Vickers micro-hardness and $\delta_{\alpha_{\text {lath }}}$ is the $\alpha$ lath thickness in $\mu \mathrm{m}$.

As demonstrated in our previous work [21], porosity is the main factor controlling tensile properties but microstructure is also important, especially for cases where porosity is close to zero. Under these circumstances, microstructure becomes the main factor influencing mechanical properties. In this work, different aging treatments have been performed for the vertically oriented specimens from a batch where porosity was considered constant for all specimens in the build. Thus, the influence of the $\alpha$ lath coarsening on tensile properties was studied. Figure 18 shows the tensile test results versus $\alpha$ lath thickness; $\alpha$ lath thickness has no relevant influence on the ultimate strength, however, there is considerable decrease in the yield strength and elongation as the $\alpha$ lath thickness increases. This can be explained considering that a decrease in $\alpha$ lath thickness reduces the effective slip length and therefore increases the yield strength.

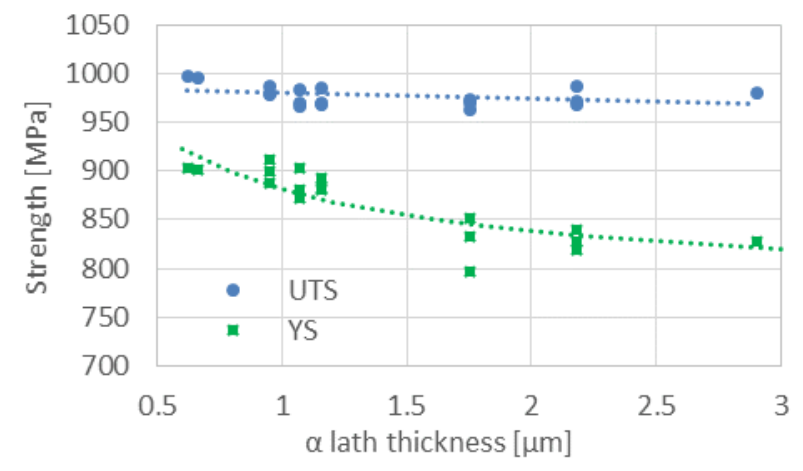

(a)

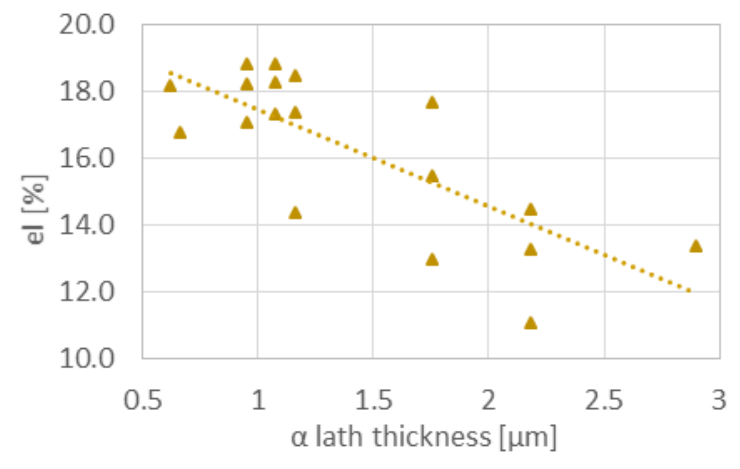

(b)

Figure 18. (a) UTS and YS versus $\alpha$ lath thickness and empirical correlations. The standard deviations were measured as $50 \mathrm{MPa}$ for the UTS and $72 \mathrm{MPa}$ for the YS. (b) Elongation versus $\alpha$ lath thickness and empirical correlation. The standard deviation was measured as $2.5 \%$.

The increase of the yield strength with the refinement of the microstructure can be explained in the same way as the increase of the hardness and modeled with a Hall-Petch equation:

$$
\sigma_{Y S}=737+144 \delta_{\alpha_{\text {lath }}}^{-1 / 2}
$$


where, $\sigma_{Y S}$ is the yield strength in MPa and $\delta_{\alpha_{\text {lath }}}$ is the $\alpha$ lath thickness in $\mu \mathrm{m}$.

The influence of the $\alpha$ lath thickness on the ultimate tensile strength is not evident, however, a linear correlation was obtained to show the slight decrease observed with the increase in the $\alpha$ lath thickness:

$$
\sigma_{U T S}=986-5.4 \delta_{\alpha_{\text {lath }}}
$$

where, $\sigma_{\text {UTS }}$ is the ultimate strength in $\mathrm{MPa}$ and $\delta_{\alpha_{\text {Iath }}}$ is the $\alpha$ lath thickness in $\mu \mathrm{m}$.

The effect of the $\alpha$ lath thickness on the elongation is more complicated in lamellar $\alpha+\beta$ titanium alloys. The refinement of the microstructure increases the elongation until it reaches a maximum peak, then it decreases drastically. This phenomenon is attributed to a change in the fracture mode from transcrystalline to intercrystalline [38]. Studying the trend of the elongation values obtained in this study, Figure 18b, only the transcrystalline mode of fracture was considered operational for the $\alpha$ lath thickness range studied in this work. Therefore, a linear correlation was developed to model the empirical relation between $\alpha$ lath thickness and tensile elongation:

$$
e l=20-2.9 \delta_{\text {alath }}
$$

where, $e l$ is the $\%$ tensile elongation and $\delta_{\alpha_{\text {lath }}}$ is the $\alpha$ lath thickness in $\mu \mathrm{m}$.

From these results it is apparent that in order to maintain the mechanical properties, particularly the ductility, of the alloy, the aging temperature should not exceed $600^{\circ} \mathrm{C}$. Below $600^{\circ} \mathrm{C}$ the growth of $\alpha$ lath thickness is minimal. Thus, in the second part of the heat treatment study, the optimization of the aging parameters was sought by applying a range of aging temperatures not exceeding $600^{\circ} \mathrm{C}\left(500^{\circ} \mathrm{C}, 550^{\circ} \mathrm{C}\right.$, and $600^{\circ} \mathrm{C}$ were chosen as a suitable range of values). The aging was carried out at each these temperatures for times of $3,4,5,6,7$, and 8 hours as shown in Figure 19. The solution heat treatment prior to the aging was kept constant for each test at $925^{\circ} \mathrm{C}$ for 1 hour followed by water-cooling.

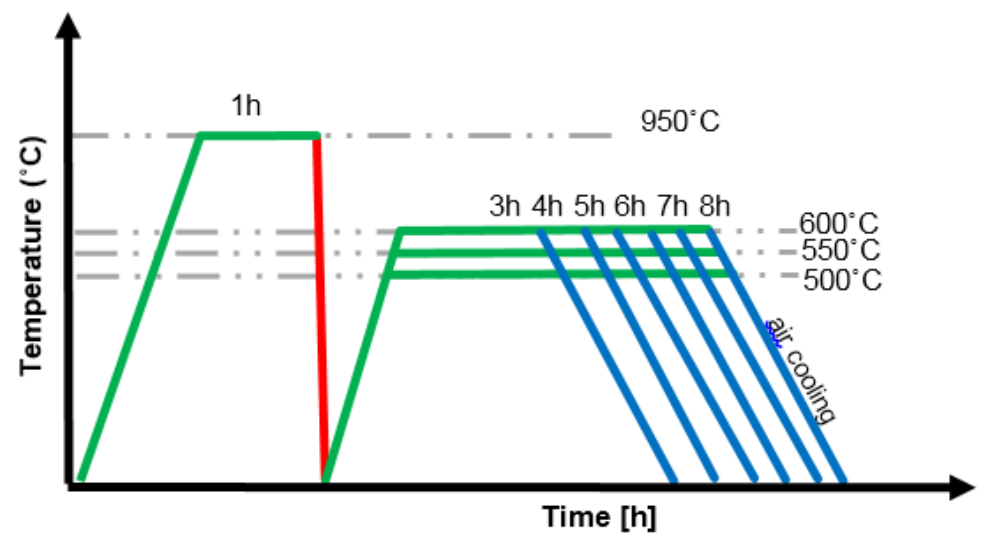

Figure 19. Temperature-time diagram of the solutionizing + aging at different aging times and temperatures.

The results of the study have been plotted in a property-time diagram, Figure 20, where UTS and elongation values are shown for different aging temperatures. In this approach, $\alpha$ lath thickness was not 
considered relevant because the aging treatments were performed at temperatures equal or below the minimum temperature $\left(600^{\circ} \mathrm{C}\right)$ that causes an appreciable $\alpha$ lath coarsening as determined in the previous approach and shown in Figure 16.

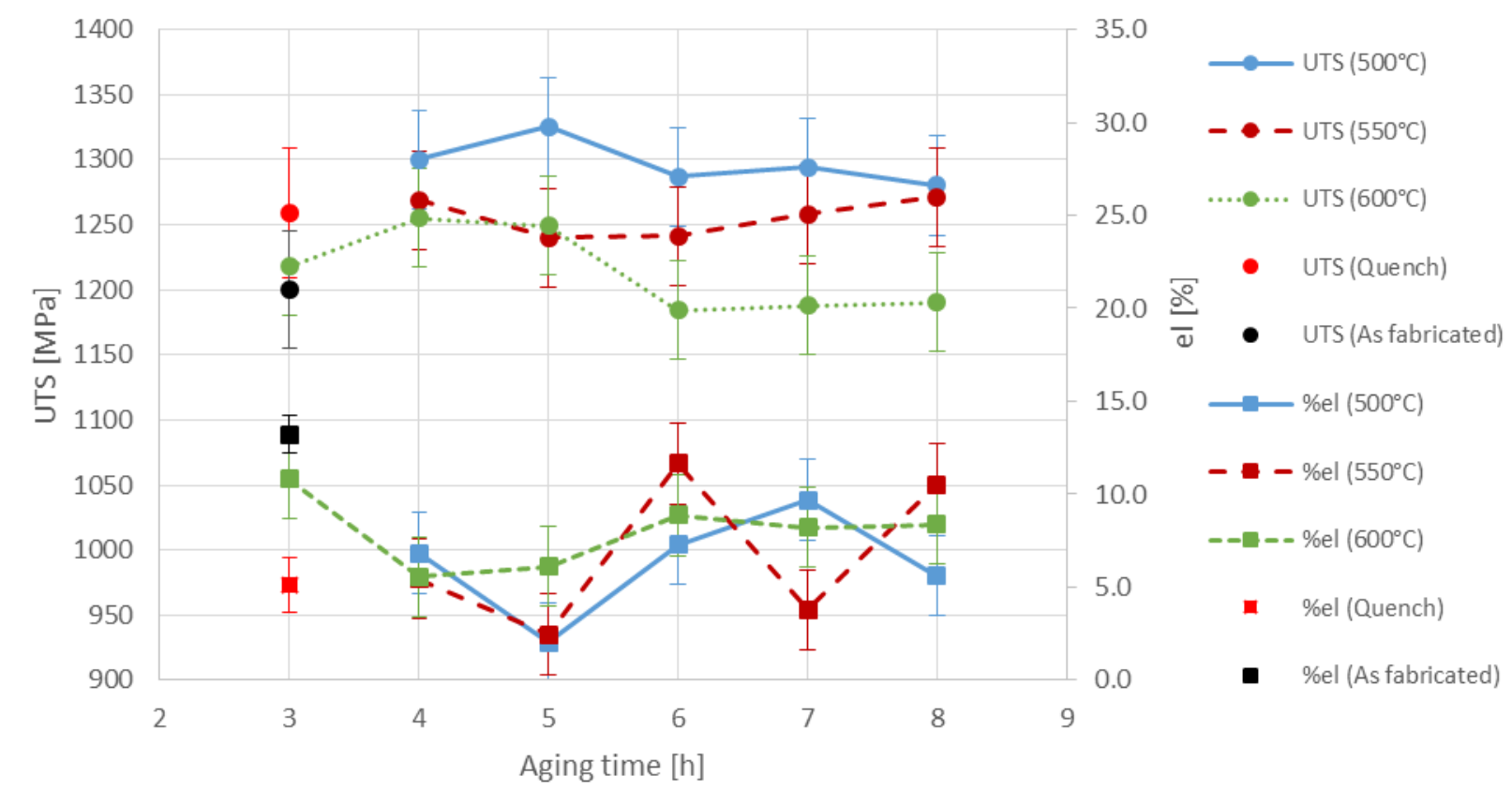

Figure 20. UTS and \% elongation values for different aging times and temperatures.

Studying the values in Figure 20, a decrease in the UTS values with increasing temperature and time can be observed. At $600^{\circ} \mathrm{C}$, the diffusion kinetics are faster than at $500^{\circ} \mathrm{C}$, which possibly results in the transformation of $\alpha^{\prime}$ martensite to $\alpha$ phase thereby causing a reduction in UTS. Therefore, with increasing time and temperature, as the transformation reaches different levels of completion, changes in UTS can be noticed. The elongation however, does not show a clear trend and the effect of the heat treatment on this property is not well understood. This is overall a complex process because up to $550^{\circ} \mathrm{C}$ $\alpha^{\prime}$ martensite starts to transform to $\alpha$ phase by diffusion and simultaneously the $\mathrm{Ti}_{3} \mathrm{Al}$ starts to precipitate in the $\alpha$ phase. More experiments have to be done in order to have a better understanding of the influence of the solutionizing and aging heat treatment on EBM Ti-6Al-4V ELI material.

Considering the results in Figure 20, it can be seen that the strength and ductility of the alloy can be altered by changing the time and temperature of the aging heat treatment. As would normally be expected, a tradeoff between strength and ductility is observed. If an application demands high strength, but ductility is not critical, then aging at $500^{\circ} \mathrm{C}$ for 5 hours to give a UTS of $1352 \mathrm{MPa}$ and an elongation of $7.3 \%$ could be a viable solution. Conversely, if high ductility is required but high strength is not required, then aging at $550^{\circ} \mathrm{C}$ for 8 hours would provide a UTS of $1271 \mathrm{MPa}$ and an elongation of $10.5 \%$. For applications where fatigue is the main design factor, the nature of the fatigue cycle needs to be considered. For example, low cycle fatigue will require higher ductility while for high cycle fatigue, higher strength is a more critical consideration. 


\section{CONCLUSIONS}

The research results presented in this study have led to the following conclusions:

- Finite element thermal simulation showed that the thermal history produced by EBM processing, as well as other powder bed fusion AM technologies, is complex due to the influence of contiguous and upper layer melting pools. The elevated build chamber temperature of the EBM process $\left(650-700^{\circ} \mathrm{C}\right)$ also plays an important role, specifically being responsible for comparatively lower residual stresses in the final part than those associated with other AM processes.

- EBM Ti-6Al-4V ELI in its as-fabricated condition was found to have a $14 \%$ higher UTS compared to the equiaxed $\alpha+\beta$ structure of conventionally processed wrought material;

- The study solutionizing heat treatments revealed that the columnar prior $\beta$ grains, characteristic of the as-fabricated condition, transform to equiaxed;

- It was observed that faster cooling rates after solution heat treatment produce a greater amount of $\alpha^{\prime}$ martensitic phase, with water-cooling at a rate of $650^{\circ} \mathrm{C} / \mathrm{sec}$ resulting in a fully $\alpha^{\prime}$ martensitic microstructure;

- The $\alpha^{\prime}$ martensite phase was found to have a considerable strengthening effect in the material, however, the ductility of the alloy decreased dramatically with the amount of $\alpha^{\prime}$. Water-cooled solution heat treated material (fully $\alpha^{\prime}$ microstructure) has 31\% higher UTS and $86 \%$ lower ductility than the furnace-cooled solution heat treated material ( $\alpha+\beta$ microstructure).

- A relationship between the aging parameters (time and temperature) and $\alpha$ lath thickness has been further developed from reference [21] and validated for a temperature range from $600-900^{\circ} \mathrm{C}$; no increase in the $\alpha$ lath thickness was observed below $600^{\circ} \mathrm{C}$;

- Increases in $\alpha$ lath thickness was found to have a detrimental effect on mechanical properties. An increase in $\alpha$ lath thickness from 0.62 to $2.9 \mu \mathrm{m}$ reduced micro-hardness, YS, UTS, and elongation by $11 \%, 8.5 \%, 1.5 \%$, and $26 \%$ respectively.

- Equations were developed to relate the $\alpha$ lath thickness to the resulting micro-hardness, YS, UTS, and elongation of EBM Ti-6Al-4V ELI material;

- Combining solutionizing and aging heat treatments indicated that mechanical properties of EBM Ti-6Al-4V ELI material can be tailored by adjusting the cooling rates, temperatures, and times of the heat treatment. Thus, an optimized heat treatment needs to be selected based on the nature of the application. Specific consideration needs to be given to the effects of heat treatments on structural properties, including fatigue and fatigue crack growth, for the future implementation of the EBM process in high-integrity applications.

\section{ACKNOWLEDGMENTS}

This research was performed under the Additive Manufacturing program of the Integrative Material Design Center (iMdc) at Worcester Polytechnic Institute, in collaboration with the Additive Manufacturing Demonstration Facility of Oak Ridge National Laboratory, and sponsored by the US Department of Energy, Office of Energy Efficiency and Renewable Energy, Advanced Manufacturing Office, under contract DE-AC05-00OR22725 with UT-Battelle, LLC. Ph.D. candidates Yuwei Zhai and Anthony Spangenberger of the iMdc also collaborated actively in the material characterization performed during this study. 


\section{REFERENCES}

[1] Y. Zhai, D.A. Lados, J.L. LaGoy, Additive manufacturing: making imagination the major limitation, JOM. 66 (2014) 808-816.

[2] ASTM-International, ASTM Standard F2792-12a: Standard Terminology for Additive Manufacturing Technologies, (2012).

[3] J. Scott, N. Gupta, C. Weber, S. Newsome, T. Wohlers, T. Caffrey, Additive manufacturing: Status and opportunities, Science and Technology Policy Institute. (2012) 1-29.

[4] D.L. Bourell, M.C. Leu, D.W. Rosen, Roadmap for additive manufacturing: identifying the future of freeform processing, The University of Texas, Austin. (2009).

[5] National Institute of Standards and Technology (NIST), Measurement Science for Metal-Based Additive Manufacturing, 2013.

[6] National Intelligence Council, Global Trends 2030: Alternative Worlds, 5 (2012).

[7] AM Platform, Additive Manufacturing: Strategic Research Agenda, 2014.

[8] T.R. Mahale, Electron beam melting of advanced materials and structures [dissertation], North Carolina State University, 2009.

[9] J. Sieniawski, W. Ziaja, K. Kubiak, M. Motyka, Microstructure and mechanical properties of high strength two-phase titanium alloys, Titanium Alloys-Advances in Properties Control. (2013) 69-80.

[10] M. Yan, P. Yu, An Overview of Densification, Microstructure and Mechanical Property of Additively Manufactured Ti-6Al-4V-Comparison among Selective Laser Melting, Electron Beam Melting, Laser Metal Deposition and Selective Laser Sintering, and with Conventional Powder, Sintering Techniques of Materials. (2015).

[11] P. Edwards, A. O'Conner, M. Ramulu, Electron beam additive manufacturing of titanium components: Properties and performance, Journal of Manufacturing Science and Engineering. 135 (2013) 061016.

[12] B.S. Bass, Validating the Arcam EBM process as an alternative fabrication method for titanium-6Al4V alloys [dissertation], North Carolina State University, 2008.

[13] L. Facchini, E. Magalini, P. Robotti, A. Molinari, Microstructure and mechanical properties of Ti-6Al$4 \mathrm{~V}$ produced by electron beam melting of pre-alloyed powders, Rapid Prototyping Journal. 15 (2009) 171-178.

[14] N. Hrabe, T. Quinn, Effects of processing on microstructure and mechanical properties of a titanium alloy (Ti-6Al-4V) fabricated using electron beam melting (EBM), Part 2: Energy input, orientation, and location, Materials Science and Engineering: A. 573 (2013) 271-277. 
[15] N. Hrabe, T. Quinn, Effects of processing on microstructure and mechanical properties of a titanium alloy (Ti-6Al-4V) fabricated using electron beam melting (EBM), Part 1: Distance from build plate and part size, Materials Science and Engineering: A. 573 (2013) 264-270.

[16] L. Murr, E. Esquivel, S. Quinones, S. Gaytan, M. Lopez, E. Martinez, et al., Microstructures and mechanical properties of electron beam-rapid manufactured Ti-6Al-4V biomedical prototypes compared to wrought Ti-6Al-4V, Materials Characterization. 60 (2009) 96-105.

[17] H. Rafi, N. Karthik, H. Gong, T.L. Starr, B.E. Stucker, Microstructures and Mechanical Properties of Ti6Al4V Parts Fabricated by Selective Laser Melting and Electron Beam Melting, Journal of Materials Engineering and Performance. 22 (2013) 3872-3883.

[18] S. Rengers, Electron Beam Melting [EBM] vs. Direct Metal Laser Sintering [DMLS], in: SAMPE Midwest Chapter, Direct Part Manufacturing Workshop, 2012.

[19] M. Svensson, U. Ackelid, A. Arcam, Titanium alloys manufactured with electron beam melting mechanical and chemical properties, in: Materials and Processes for Medical Devices Conference(MDM V), ASM International, Minneapolis, MN, 2010: pp. 189-194.

[20] S.K. Kar, Modeling of mechanical properties in alpha/beta-titanium alloys, 2005.

[21] H. Galarraga, D.A. Lados, R.R. Dehoff, M.M. Kirka, P. Nandwana, Effects of the microstructure and porosity on properties of Ti-6Al-4V ELI alloy fabricated by electron beam melting (EBM), Additive Manufacturing. 10 (2016) 47-57.

[22] S. Hashmi, Comprehensive Materials Processing, Newnes, 2014.

[23] P. Nandwana, W.H. Peter, R.R. Dehoff, L.E. Lowe, M.M. Kirka, F. Medina, et al., Recyclability study on Inconel 718 and Ti-6Al-4V powders for use in electron beam melting, Metallurgical and Materials Transactions B. (2015) 1-9.

[24] ASTM-International, ASTM Standard F136-13: Standard Specification for Wrought Titanium6Aluminum-4Vanadium ELI (Extra Low Interstitial) Alloy for Surgical Implant Applications, (2003).

[25] Ti6Al4V ELI Titanium Alloy data sheet, (n.d.). www.arcam.com

[26] Buehler SumMet, The Sum Of Our Experience A Guide to Materials Perparation and Analysis, Second Edition, 2013

[27] G. Vander Voort, A. Roosz, Measurement of the interlamellar spacing of pearlite, Metallography. 17 (1984) 1-17.

[28] ASTM-International, ASTM Standard E384-11: Standard Test Method for Knoop and Vickers Hardness of Materials, (2011)

[29] ASTM-International, ASTM Standard E8/E8M-09: Standard Test Methods for Tension Testing of Metallic Materials, (2009). 
[30] A. Safdar, L.-Y. Wei, A. Snis, Z. Lai, Evaluation of microstructural development in electron beam melted Ti-6Al-4V, Materials Characterization. 65 (2012) 8-15.

[31] B. Cheng, S. Price, J. Lydon, K. Cooper, K. Chou, On Process Temperature in Powder-Bed Electron Beam Additive Manufacturing: Model Development and Validation, Journal of Manufacturing Science and Engineering. 136 (2014) 061018.

[32] S. Price, J. Lydon, K. Cooper, K. Chou, Experimental temperature analysis of powder-based electron beam additive manufacturing, in: Proceedings of the Solid Freeform Fabrication Symposium, 2013: pp. 162-173.

[33] S. Al-Bermani, M. Blackmore, W. Zhang, I. Todd, The origin of microstructural diversity, texture, and mechanical properties in electron beam melted Ti-6Al-4V, Metallurgical and Materials Transactions A. 41 (2010) 3422-3434.

[34] M. Zäh, S. Lutzmann, M. Kahnert, F. Walchshäusl, Determination of Process Parameters for Electron Beam Sintering (EBS), in: Excerpt from the Proceedings of the COMSOL Conference Hannover, 2008.

[35] ISO-ASTM, ISO/ASTM 52921:2013: Standard Terminology for Additive Manufacturing-Coordinate Systems and Test Methodologies, (2013).

[36] J.K. Ervin, Post Heat Treatment Effects of Ti-6Al-4V Produced via Solid Freeform Electron Beam Melting, 2008.

[37] J. Sieniawski, W. Ziaja, K. Kubiak, M. Motyka, Titanium Alloys-Advances in Properties Control, 2013.

[38] G. Lütjering, J.C. Williams, Titanium, Springer, 2003.

[39] M.J. Donachie, Titanium: a technical guide, ASM international, 2000.

[40] R. Pederson, Microstructure and Phase Transformation of Ti-6Al-4V, 2002.

[41] B. Vrancken, L. Thijs, J.-P. Kruth, J. Van Humbeeck, Heat treatment of Ti6Al4V produced by Selective Laser Melting: Microstructure and mechanical properties, J. Alloys Compd. 541 (2012) 177-185.

[42] R. Abbaschian, R. Reed-Hill, Physical metallurgy principles, Cengage Learning, 2008.

[43] D.A. Porter, K.E. Easterling, M. Sherif, Phase Transformations in Metals and Alloys, (Revised Reprint), CRC press, 2009.

[44] M. Jamshidinia, M.M. Atabaki, M. Zahiri, S. Kelly, A. Sadek, R. Kovacevic, Microstructural modification of Ti-6Al-4V by using an in-situ printed heat sink in Electron Beam Melting (EBM), Journal of Materials Processing Technology. 226 (2015) 264-271. 